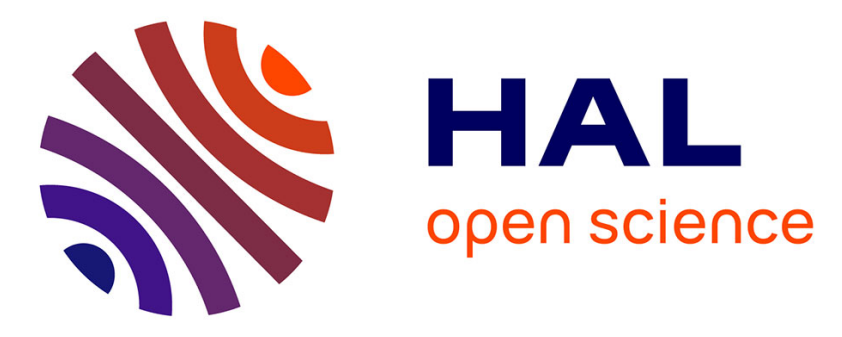

\title{
Light-induced piston nanoengines: ultrafast shuttling of a styryl dye inside cucurbit[7]uril
}

Ekaterina y Chernikova, Daria V Berdnikova, Yuri V Fedorov, Olga A. Fedorova, François Maurel, Gediminas Jonusauskas

\section{To cite this version:}

Ekaterina y Chernikova, Daria V Berdnikova, Yuri V Fedorov, Olga A. Fedorova, François Maurel, et al.. Light-induced piston nanoengines: ultrafast shuttling of a styryl dye inside cucurbit[7]uril. Physical Chemistry Chemical Physics, 2017, 19 (38), pp.25834-25839. 10.1039/C7CP04283C . hal01627994

\section{HAL Id: hal-01627994 \\ https://hal.science/hal-01627994}

Submitted on 2 Nov 2017

HAL is a multi-disciplinary open access archive for the deposit and dissemination of scientific research documents, whether they are published or not. The documents may come from teaching and research institutions in France or abroad, or from public or private research centers.
L'archive ouverte pluridisciplinaire HAL, est destinée au dépôt et à la diffusion de documents scientifiques de niveau recherche, publiés ou non, émanant des établissements d'enseignement et de recherche français ou étrangers, des laboratoires publics ou privés. 


\title{
Light-induced piston nanoengines: ultrafast shuttling of a styryl dye inside cucurbit[7]uril $\dagger$
}

\author{
Ekaterina Y. Chernikova, *a Daria V. Berdnikova, ab Yuri V. Fedorov, a Olga A. Fedorova, \\ a François Maurel ${ }^{c}$ and Gediminas Jonusauskas \\ d
}

The combination of photoactive styryl(pyridinium) dyes and cucurbit[7]uril (CB[7]) in an integrated supramolecular system allowed us to design a novel high speed molecular machine based on the fully reversible shuttling motion of the dye inside the $\mathrm{CB}$ [7] host cavity. The driving force of this movement is the electrostatic potential change after the occurrence of intramolecular charge transfer in the excited state of the dye molecule that can be externally controlled by light. Steady-state and time-resolved optical spectroscopy as well as DFT calculations provided an unambiguous evidence for the ultrafast piston-like movement of the system between two states. The shuttling process occurs in the picosecond timescale and its bistability depends on the strength of the dye donor fragment.

The creation of artificial nanoscale machines, such as molecular rotary motors, muscles, and switches, that mimic actions of natural biofragments is a highly topical research area of modern supramolecular chemistry. ${ }^{1-5}$ The ongoing interest in synthetic molecular machines not only arises from the desire to understand mechanisms of the formation and functioning of biological structures but is also supported by their potential applications in designing smart molecular devices, targeted drug delivery systems and various functional assemblies.

Molecular shuttles constructed from ring-shaped host molecules that encircle rod-like guest molecules due to non-covalent interactions and can reversibly switch the position between

\footnotetext{
${ }^{a}$ A. N. Nesmeyanov Institute of Organoelement Compounds,

Russian Academy of Sciences, Vavilova str. 28, 119991 Moscow, Russia.

Email: chernikova@ineos.ac.ru

${ }^{b}$ Peoples Friendship University of Russia (RUDN University),

Mikluho Maklaya str. 6, 117198 Moscow, Russia

${ }^{c}$ Université Paris Diderot, Sorbonne Paris Cité, ITODYS, UMR CNRS 7086,

15 rue Jean Antoine de Balf, 75205 Paris, France

${ }^{d}$ Laboratoire Ondes et Matière d'Aquitaine UMR CNRS 5798,

Bordeaux University, 351 Cours de la Libération, 33405 Talence, France

$\dagger$ Electronic supplementary information (ESI) available: Materials, equipment, experi mental procedures, additional steady state and time resolved optical spectroscopy data, optimization and TD DFT results. See DOI: 10.1039/c7cp04283c
}

two stable points sliding along the guest are of particular importance. ${ }^{6-10}$ Aiming for the construction of artificial molecular shuttles, we focused our attention on cucurbit $[n]$ urils $(\mathrm{CB}[n])$ as the preferred host molecules. In the majority of $\mathrm{CB}[n]$-based systems, the control of the shuttling process is performed by various external stimuli such as changes in $\mathrm{pH}$, redox states, and temperature. ${ }^{11,12}$ Surprisingly, the examples of light-responsive $\mathrm{CB}[n]$-based shuttles are still rather rare, although the excited state properties of $\mathrm{CB}[n]$-guest complexes upon light irradiation were a subject of extensive investigations. ${ }^{13-21}$ Thus, photoresponsive $\mathrm{CB}[n]$-based shuttling systems operated by photochemical $E-Z$ isomerization of azobenzene derivatives ${ }^{22,23}$ or photoinduced electron transfer in pseudorotaxanes ${ }^{24-26}$ were reported. The reversibility of the latter systems, however, is usually achieved only in the presence of a photosensitizer or/and a sacrificial reductant. ${ }^{24-26}$

In this paper, we combine the knowledge in the field of $\mathrm{CB}[n]$-based molecular shuttles and excited state properties to design the light-controlled systems where the shuttling process occurs without any chemical rearrangement and produces no waste. Herein we describe an elegantly simple approach towards the design of a high speed molecular shuttle based on photoactive molecules 1 and 2 and a macrocyclic $\mathrm{CB}[7]$ host (Chart 1). Notably, the switching is based on the photoinduced intramolecular charge transfer (ICT) process that is characteristic

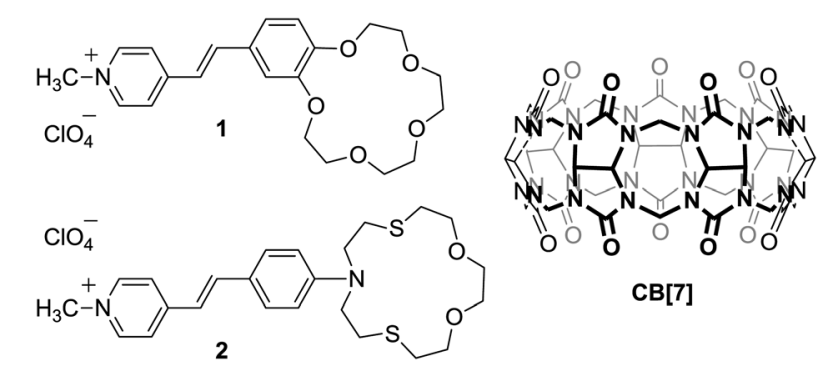

Chart 1 Chemical structures of styryl(pyridinium) dyes 1 and 2 and cucurbit[7]uril. 
Table 1 Spectroscopic data for free dyes 1 and 2 and their complexes with $\mathrm{CB}[7]$ in $\mathrm{H}_{2} \mathrm{O}$ at $20^{\circ} \mathrm{C}$

\begin{tabular}{llllll}
\hline Compound & $\lambda_{\text {abs }} / \mathrm{nm}$ & $\varepsilon / \mathrm{M}^{-1} \mathrm{~cm}^{-1}$ & $\lambda_{\mathrm{fl}} / \mathrm{nm}$ & $\varphi_{\mathrm{fl}}$ & $\tau_{\mathrm{fl}} / \mathrm{ps}$ \\
\hline $\mathbf{1}$ & $382^{a}$ & 27000 & $545^{a}$ & $0.026^{a}$ & $122,355^{a}$ \\
$\mathrm{CB}[7] \mathbf{1}$ & $407^{a}$ & 23500 & $525^{a}$ & $0.032^{a}$ & $470^{a}$ \\
& & & & & \\
$\mathbf{2}$ & $456^{b}$ & 28100 & 608 & 0.011 & 77 \\
$\mathrm{CB}[7] 2$ & $482^{b}$ & 26300 & 598 & 0.230 & 1700 \\
${ }^{a}$ Data obtained in ref. $33 .{ }^{b}$ Data obtained in ref. 34. &
\end{tabular}

of the highly polar $\pi$-conjugated D-A dye molecules. ${ }^{27}$ Considering the affinity of $\mathrm{CB}[7]$ towards cationic species, ${ }^{28-30}$ we assumed that the photoinduced ICT-based displacement of the positive charge from the pyridinium ring to an oxygen (dye 1) or nitrogen (dye 2) atom of the aryl fragment will shift $\mathrm{CB}[7]$ along the dye from the pyridinium moiety towards the styryl fragment in the exited state. The $N$-methyl-4-styryl(pyridinium) dyes bearing O-donor (dye 1) and $\mathrm{N}$-donor (dye 2) atoms were synthesized according to the published protocols. ${ }^{31,32}$ Derivatization with crown ether residues increases the solubility of the dyes in an aqueous medium. The binding properties of 1 and 2 with $\mathrm{CB}[7]$ in aqueous solution were the subject of our previous studies. ${ }^{33,34}$ UV-vis and NMR spectroscopy data confirmed the formation of the stable inclusion 1:1 complexes $\mathrm{CB}[7]-\mathbf{1}$ and $\mathrm{CB}[7]-2$ driven by a hydrophobic effect and ion-dipole interactions with preferential immersion of the vinyl(pyridinium) unit of dyes $\mathbf{1}$ and $\mathbf{2}$ into the $\mathrm{CB}[7]$ cavity (Table 1). The identical complexation pattern resulted in the equal stability constant value of $\log K=5.36 \pm 0.02$ for both dyes $\mathbf{1}$ and $\mathbf{2}$.

It is well known that photophysical characteristics (e.g. emission spectra, fluorescence intensity and lifetimes) of chromophoric guest molecules are influenced by their positioning in the $\mathrm{CB}[7]$ host cavity. ${ }^{13,16,35-37}$ Since the binding site for $\mathrm{CB}[7]$ is the same in the host-guest complexes of $\mathrm{CB}[7]$ with dyes $\mathbf{1}$ and $\mathbf{2}$, one can assume that the complexation-induced fluorescence changes should be similar in both cases. However, the experimentally observed fluorescence emission changes upon complexation of dyes $\mathbf{1}$ and $\mathbf{2}$ with $\mathrm{CB}[7]$ are specific for each dye (Table 1). Thus, the addition of $\mathrm{CB}[7]$ to the solution of 1 caused a moderate blue shift $(\Delta \lambda=20 \mathrm{~nm})$ of the emission band along with a slight enhancement of the fluorescence quantum yield (ca. 1.2-fold). ${ }^{33}$ In contrast, the binding of 2 to $\mathrm{CB}[7]$ resulted in a significant enhancement of the dye fluorescence ( $c a$. 20-fold) with a less pronounced blue shift $(\Delta \lambda=10 \mathrm{~nm})$ of the guest fluorescence maximum.

We used DFT calculations to analyze the evolution of charge distribution in free dyes $\mathbf{1}$ and $\mathbf{2}$ while going from the ground to the first excited state (Table S1, S2 and Fig. S3, S4, ESI $\dagger$ ). It was clearly shown that in the ground state $\mathrm{S}_{0}$ the positive charge in $\mathbf{1}$ and $\mathbf{2}$ is mainly localized on the pyridinium fragments. In the excited state $\mathrm{S}_{1}$ of $\mathbf{1}$ and 2 , the charge transfer of $0.33|e|$ takes place from the phenyl ring to the pyridinium fragment, whereas the ethylene bridge keeps a constant charge value. Consequently, the electronic excitation to the first excited state leads to a decreasing positive charge on the pyridinium groups and an increasing positive charge on the dimethoxyphenyl (dye 1) or dimethylaminophenyl (dye 2) moieties, which is anticipated for the ICT phenomenon. It is expected that such redistribution of charge will change the binding site for $\mathrm{CB}[7]$ that promotes the displacement of the excited dye molecule in the $\mathrm{CB}[7]$ cavity.

The formation of $\mathrm{CB}[7]-\mathbf{1}$ and $\mathrm{CB}[7]-\mathbf{2}$ inclusion complexes also was studied using DFT calculations. The large size of the cucurbituril host-guest complexes makes the quantum chemical investigation of the excited state computationally demanding. Therefore, to study the inclusion complex formation and locate possible minimum energy structures, we performed an energy scan calculation with both the isolated host and guest kept frozen at the optimized structure corresponding to the isolated molecules. Therefore, we calculated the evolution of the energy with respect to a scan coordinate $(d)$ chosen as a distance between the carbon atom of the methyl group of $\mathbf{1}$ or $\mathbf{2}$ and a dummy atom located in the center of mass of the $\mathrm{CB}[7]$ cavity. A detailed description of the DFT calculations is given in the ESI. $\dagger$

The obtained potential energy curves allowed the identification of one minimum energy structure for the complexation of dye 1 with $\mathrm{CB}[7]$ and two minimum energy structures with dye 2 (Fig. S5 and S6, ESI $\dagger$ ). Notably, the inclusion of 1 or 2 in the $\mathrm{CB}[7]$ cavity occurs either barrierless or with just a very low energy barrier. For dye 1, the inclusion process in $\mathrm{CB}[7]$ is associated with a strong decrease of the energy from the initial structure $(d=0 \AA)$ to the minimum energy structure $(d=4.2 \AA)$, in which the interaction energy $\Delta E_{\text {int }}$ is found to be $-13.3 \mathrm{kcal} \mathrm{mol}^{-1}$. The structure of the complex with the minimum energy shows that the pyridinium moiety of $\mathbf{1}$ is completely inside the $\mathrm{CB}[7]$ cavity and the electrostatic interaction between the pyridinium and the oxygen portal of $\mathrm{CB}[7]$ takes place. The presence of the only minimum on the potential energy curve does not support the formation of another stable configuration for the complex, therefore making bistable shuttling of dye 1 inside the $\mathrm{CB}[7]$ cavity questionable. At the same time, the inclusion process of 2 with $\mathrm{CB}[7]$ shows two minima, A and B (Fig. S6, ESI $\dagger$ ), located at distances $d=3.4 \AA$ and $6.2 \AA$, respectively. Minimum A is more stable than B by $10.9 \mathrm{kcal} \mathrm{mol}^{-1}$ in the ground state $S_{0}$ and by $8.6 \mathrm{kcal} \mathrm{mol}^{-1}$ in the first excited state $\mathrm{S}_{1}$. The interaction energy $\Delta E_{\text {int }}$ calculated in the lowest minimum $\mathrm{A}$ in the ground state is $-9.8 \mathrm{kcal} \mathrm{mol}^{-1}$. This value is somewhat greater than the interaction energy obtained in the $\mathrm{CB}[7]-\mathbf{1}$ complex, indicating that under the conditions used for the calculations dye $\mathbf{2}$ is more weakly bound to $\mathrm{CB}[7]$ than 1 .

As it was mentioned above, the energy scan curves were obtained using a frozen geometry of the host and guest molecules. The geometries of inclusion complexes A and B were then fully optimized in the ground $S_{0}$ and excited $S_{1}$ states for the $\mathrm{CB}[7]-2$ complex. After optimization, complex A was found to be more stable than B by $0.8 \mathrm{kcal} \mathrm{mol}^{-1}$ in the ground state while B is more stable than A by $2.9 \mathrm{kcal} \mathrm{mol}^{-1}$ in the $\mathrm{S}_{1}$ state. From the calculations, it can be, therefore, anticipated that the displacement of 2 in the cavity can be induced by electronic excitation from the position $\mathrm{A}(d=3.4 \AA)$ to $\mathrm{B}(d=6.2 \AA)$ leading to a total displacement of $2.8 \AA$ as shown in Fig. 1. Eventually, it means that upon light excitation dye 2 moves inside the $\mathrm{CB}[7]$ cavity like a 


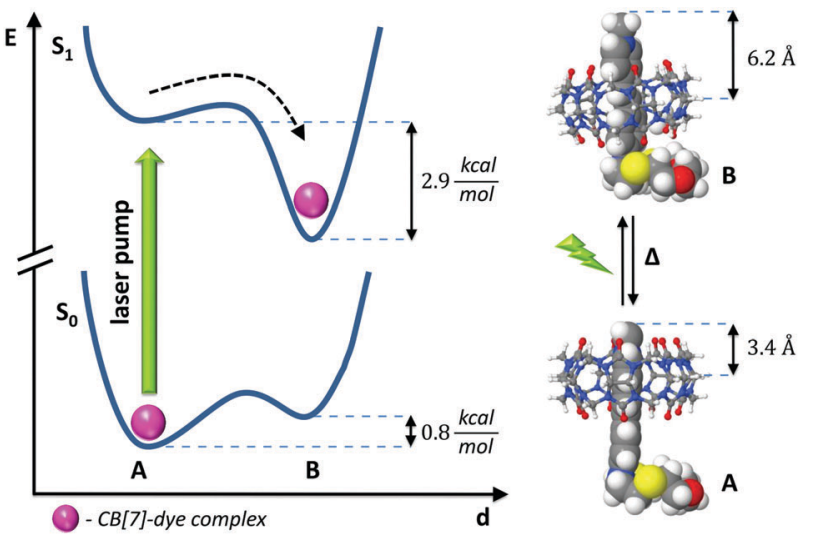

Fig. 1 Schematic representation of potential energy curves of CB[7] 2 in the ground $S_{0}$ and excited $S_{1}$ states and illustration of the moving principle of the light induced molecular shuttle based on the ICT process.

piston in a cylinder. The reverse movement of $\mathrm{CB}[7]$ occurs spontaneously as soon as the dye molecule relaxes from the excited to the ground state.

Taking into account the results of DFT calculations, all further experimental studies were performed for the $\mathrm{CB}[7]-2$ system. The processes occurring in the excited state of 2 were examined in detail. Thus, dye 2 possesses low fluorescence quantum yields $\left(\varphi_{\mathrm{fl}}=0.011\right)$ in aqueous solution (Table 1$)$ and is known to undergo very fast non-radiative relaxation of the excited state through the formation of a twisted intramolecular charge transfer (TICT) state in polar solvents. ${ }^{32}$ In the case of amino(styryl)pyridinium derivatives, three possibilities with different activation energies for rotating processes were reported. ${ }^{38-41}$ Thus, for dye 2, the rotation about the aniline-ethylene bond should be the easiest one since it would have to possess the lowest energy barrier to rotation in the $\mathrm{S}_{1}$ state. The rotation about the pyridyl-ethylene bond is also possible but not favored in solvents with high dielectric constants (e.g. water). Finally, the rotation of the crown-derived dimethylamino group should be the most hindered one due to the fragment bulkiness and, therefore, the highest potential barrier. Therefore, the rotation about the dimethylaminophenyl-ethylene single bond and the passage through the TICT state involving a "loose bolt" relaxation mechanism of the excited state revealed to be the main pathway for the non-radiative decay of dye $\mathbf{2}$ (see details in the ESI, $\dagger$ Section $\mathrm{S7}$ ). ${ }^{39-41}$ It should be noted that the high-energy barrier to rotation about the double bond in the $S_{1}$ state prevents the photoisomerization of dye 2 in most polar solvents. ${ }^{42-44}$

To determine the energy barrier for the non-radiative relaxation of dye 2 and complex $\mathrm{CB}[7]-2$, temperature dependent studies of fluorescence quantum yields were performed using the modified Arrhenius equation (see details in the ESI, $\uparrow$ Section S5). ${ }^{42-44}$ Thus, the activation energy values for 2 and $\mathrm{CB}[7]-2$ have been estimated to be $\Delta E_{\mathrm{a}}=3.9 \pm 0.3 \mathrm{kcal} \mathrm{mol}^{-1}$ $\left(16.2 \pm 1.1 \mathrm{~kJ} \mathrm{~mol}^{-1}\right)$ and $\Delta E_{\mathrm{a}}=3.8 \pm 0.2 \mathrm{kcal} \mathrm{mol}^{-1}(15.9 \pm$ $0.6 \mathrm{~kJ} \mathrm{~mol}^{-1}$ ), respectively. It can be seen that the activation barriers for the non-radiative deactivation process in the excited state of dye 2 and complex $\mathrm{CB}[7]-2$ are close to each other and also to the activation energy of the viscous flow for pure water, $15.9 \mathrm{~kJ} \mathrm{~mol}^{-1}{ }^{45}$ In other words, in water the TICT process occurs without any barrier in both free dye 2 and its complex $\mathrm{CB}[7]-2$. Nevertheless, it was found that the Arrhenius pre-exponential factor decreases by two orders of magnitude upon complexation from $1.1 \times 10^{13}$ to $2.2 \times 10^{11}$. According to the theory of the activated complex for unimolecular reactions ${ }^{46}$ the decrease of the Arrhenius pre-exponential factor indicates that the probability of the TICT state formation for complex $\mathrm{CB}[7]-\mathbf{2}$ is lower than that for free dye $\mathbf{2}$. From the physical point of view, it can be explained by the decrease of the number of efficient collisions of $\mathbf{2}$ with water molecules leading to the twisting of 2. Eventually, it means that in the excited state of the complex $\mathrm{CB}[7]$ is shifted towards the phenyl ring, thus shielding the aniline-ethylene bond from the polar solvent and hindering its twisting. The importance of changes of the pre-exponential factor on reaction kinetics has previously been found for various compounds. ${ }^{38,47}$

To characterize the dynamics of the excited state relaxation and provide further insight into the light-induced movement of the dye 2 molecule inside the $\mathrm{CB}[7]$ cavity, the femtosecond transient absorption spectroscopy (TRABS) was applied (see details in the ESI, $\dagger$ Section S6). ${ }^{48}$ A characteristic result of a pump-probe TRABS experiment for 2, i.e. a map of absorbance changes after light excitation in delay-wavelength coordinates, is displayed in Fig. 2a. Here, two essential features can be clearly observed. Firstly, there is a positive band at about $520 \mathrm{~nm}$ corresponding to the excited state absorption (ESA), which appears together with the pump pulse. Most importantly, one may note a stimulated emission (SE) band in the wavelength region of $560-660 \mathrm{~nm}$, which is associated with the fluorescence of dye 2. The maximum of the SE band undergoes a noticeable red shift with increasing time delay. The changes of the SE band position during the first few picoseconds represent the dynamic solvation that is environment (solvent) reorganisation around the dye molecules. The dynamic solvation is a result of the dye dipole moment change after the ICT process occurred upon excitation. The reorganisation of the dye environment lowers the potential energy of the solute-solvent system in the excited state and, therefore, induces the red shift of the SE band.

A graphical representation of the SE band maximum displacement with time for free dye 2 is illustrated in Fig. $2 b$ and Fig. S13a, ESI. $\dagger$ In general, the solvation dynamics in water is
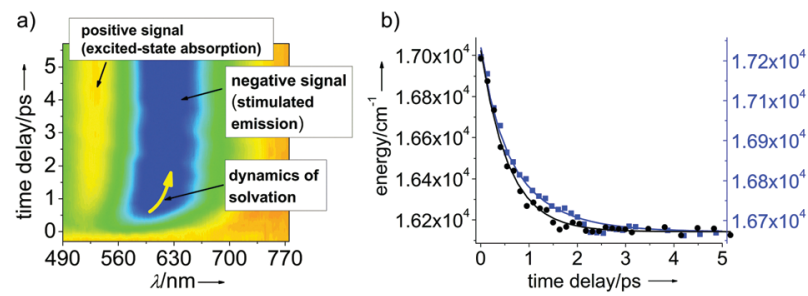

Fig. 2 (a) TRABS map for dye 2 in $\mathrm{H}_{2} \mathrm{O}$ measured upon $470 \mathrm{~nm}$ laser excitation in the $490780 \mathrm{~nm}$ spectral range and (b) the kinetic traces of the stimulated emission displacement during first several picoseconds for dye $\mathbf{2}$ (black circles) and its complex CB[7] 2 (blue squares), measured using the femtosecond time resolved pump probe technique. 


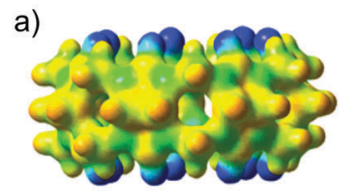

b)

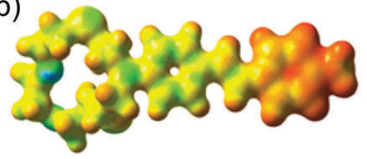

c)
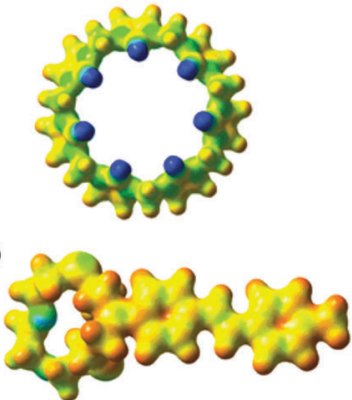

Fig. 3 Electrostatic potential surface of: (a) CB[7] (top and side views), (b) dye $\mathbf{2}$ in the ground state and (c) dye $\mathbf{2}$ in the excited $\mathrm{S}_{1}$ state.

non-monoexponential and includes at least three components: $0.1 \mathrm{ps}$ (inertial motion), $0.3-0.7 \mathrm{ps}$ and $1.4-3.5 \mathrm{ps}$ for dyes of different natures (cationic, anionic and neutral). ${ }^{49-51}$ The average solvation time constant for all the dyes studied in the work $^{51}$ was in the range of $0.43-0.48$ ps and was almost independent of the nature of the solute. We fitted the corresponding kinetic decay curve (black circles) to a biexponential function by using $0.34 \mathrm{ps}$ (dominant contribution) and $0.97 \mathrm{ps}$ time constants. The first time constant represents the average between the inertial motion of water and the first rotational movement of the water molecule. The second time constant in our fit corresponds to the third time constant discussed above.

As soon as dye 2 was confined in the $\mathrm{CB}[7]$ cavity, no time constant of 0.34 ps corresponding to the solvation in water was found. The displacement of the SE band in this case is slower with the time constant of approximately 0.57 ps (Fig. 2b, blue squares, and Fig. S13b, S14, ESI $\dagger$ ). Since CB[7] acts like a new environment for the dye molecules, the displacement of the SE band represents now the rearrangement of the $\mathrm{CB}[7]-2$ system in the excited state in order to lower the overall potential energy of the system.

We attribute the time constant of 0.57 ps to the movement of the guest in the cavity of the host because upon excitation a new positive charge distribution should be followed by the reaction of the negatively charged inner rims of $\mathrm{CB}$ [7] (Fig. 3). This means that the electrostatic attraction is weakened on the side of the pyridinium subunit of the dye in the excited state due to the positive charge transfer towards the phenyl subunit. As shown in Fig. S4 (ESI $\dagger$ ), the positive charge drops from 0.84 to 0.49 on the pyridinium when going from the ground state to the excited state for dye 2 . An increase of the positive charge on the phenyl subunit (from 0.22 to 0.59 ) now exerts a much stronger attraction of the closer $\mathrm{CB}[7]$ rim than that in the ground state. This must be followed by the movement of the relatively rigid cucurbituril molecule in order to adapt the position of negatively charged oxygen rims with respect to the new distribution of positive charges and thus reduce the potential energy of the complex.

The fluorescence data also support the hypothesis that the emission takes place from such a complex geometry where $\mathrm{CB}[7]$ is located on the dimethylaminophenyl fragment of dye 2 .

We, therefore, deduced that the time constant obtained from kinetics analysis as $0.57 \mathrm{ps}$ for the $\mathrm{CB}[7]-2$ complex can be reliably assigned to the dye molecule movement time inside the $\mathrm{CB}[7]$ cavity.

Proceeding from the solvation time constant and the estimated distance separating two binding sites of $\mathrm{CB}[7](2.8 \AA$ from the DFT calculations) in the ground and excited states we deduced the average rate of the movement of dye 2 versus $\mathrm{CB}$ [7]. Thus, the displacement rate for dye 2 in the $\mathrm{CB}$ [7] cavity is $0.49 \mathrm{~nm} \mathrm{ps}^{-1}\left(490 \mathrm{~m} \mathrm{~s}^{-1}\right)$. As soon as the excited state of the dye is relaxed, the ground state charge distribution is restored, which causes the backward movement of the dye molecule inside the cavity until the initial $\mathrm{CB}$ [7] binding site is reached. Evidently, this light-driven shuttling process is fully reversible and can be repeated over many cycles.

From the above analysis we finally conclude that the lightinduced movement in the $\mathrm{CB}[7]-2$ system is the ultrafast process and it clearly not only depends on the thermodynamic parameters but also - and, probably, principally - is driven by the electrostatic force arising from the dipole moment change in the excited state of the encapsulated dye. The strength of the donor substituent in the phenyl ring of the dye is a crucial factor influencing the dye moving inside the $\mathrm{CB}$ [7] cavity. It should be also noted that the operation rate of our lightinduced molecular shuttle ( 0.57 ps for forward movement) is faster than those of the earlier described pseudorotaxane systems by four-to-six orders of magnitude (1-100 $\mu$ s for forward movement). ${ }^{52,53}$

\section{Conclusions}

To sum up, we have constructed an ultrafast piston nanoengine based on the light-induced movement of styryl(pyridinium) dye 2 inside the $\mathrm{CB}[7]$ cavity. The driving force of the movement is the ICT process occurring in the dye molecule upon photoexcitation. The shuttling motion of the system between two states is controlled solely by the light stimulus and is fully reversible. Bistability of the present system is achieved through different binding sites for $\mathrm{CB}[7]$ in the ground and excited states of the $\mathrm{CB}[7]-2$ complex. The described moving principle may be used for the creation of advanced molecular machines and devices possessing ultrahigh rates or for nanoflappers in drug delivery and release systems. To further develop this idea, structural variations of the photoactive constituent, namely, lengthening of the linker between the pyridinium and crown ether moieties or changing the strength of the donor/acceptor groups will be applied to create systems with tunable moving time parameters.

\section{Conflicts of interest}

The authors declare no competing financial interest. 


\section{Acknowledgements}

This work was supported by the Russian Foundation for Basic Research grant 16-03-00423 (Y. V. F.) and by the CNRS, Université Bordeaux and Région Aquitaine (G. J.). The publication was financially supported by the Ministry of Education and Science of the Russian Federation (the Agreement number 02.a03.0008). We thank Prof. Lyle Isaacs (University of Maryland, USA) for his friendly help and providing cucurbit[7]uril for our study. We thank Prof. Dr Heiko Ihmels (Universität Siegen, Germany) for valuable advices during the manuscript preparation.

\section{References}

1 M. M. Boyle, R. A. Smaldone, A. C. Whalley, M. W. Ambrogio, Y. Y. Botros and J. F. Stoddart, Chem. Sci., 2011, 2, 204.

2 K. Kinbara and T. Aida, Chem. Rev., 2005, 105, 1377.

3 S. F. M. Dongen, S. Cantekin, J. A. A. W. Elemans, A. E. Rowan and R. J. M. Nolte, Chem. Soc. Rev., 2014, 43, 99.

4 A. C. Fahrenbach, S. C. Warren, J. T. Incorvati, A.-J. Avestro, J. C. Barnes, J. F. Stoddart and B. A. Grzybowski, Adv. Mater., 2013, 25, 331.

5 S. Erbas-Cakmak, D. A. Leigh, C. T. McTernan and A. L. Nussbaumer, Chem. Rev., 2015, 115, 10081.

6 S. Silvi, M. Venturi and A. Credi, J. Mater. Chem., 2009, 19, 2279.

7 D.-H. Qu, Q.-C. Wang, Q.-W. Zhang, X. Ma and H. Tian, Chem. Rev., 2015, 115, 7543.

8 M. Xue, Y. Yang, X. Chi, X. Yan and F. Huan, Chem. Rev., 2015, 115, 7398.

9 V. Balzani, A. Credi and M. Venturi, Chem. Soc. Rev., 2009, 38, 1542.

10 V. Balzani, A. Credi and M. Venturi, Molecular Devices and Machines: Concepts and Perspectives for the Nanoworld, Wiley-VCH, Weinheim, Germany, 2nd edn, 2008, p. 401.

11 L. Zhu, M. Zhu and Y. Zhao, ChemPlusChem, 2017, 82, 30.

12 E. Masson, X. Ling, R. Joseph, L. Kyeremeh-Mensah and X. Lu, RSC Adv., 2012, 2, 1213.

13 R. N. Dsouza, U. Pischel and W. M. Nau, Chem. Rev., 2011, 111, 7941.

14 M. Sayes and H. Pal, J. Mater. Chem. C, 2016, 4, 2685.

15 N. Barooah, J. Mohanty, H. Pal and A. C. Bhasikuttan, Org. Biomol. Chem., 2012, 10, 5055.

16 Z. Li, S. Sun, F. Liu, Y. Pang, J. Fan, F. Song and X. Peng, Dyes Pigm., 2012, 93, 1401.

17 N. K. Petrov, D. A. Ivanov, Y. A. Shandarov, I. V. Kryukov, A. A. Ivanov, M. V. Alfimov, N. A. Lobova and S. P. Gromov, Chem. Phys. Lett., 2016, 647, 157.

18 A. Singh, W.-T. Yip and R. L. Halterman, Org. Lett., 2012, 14, 4046.

19 N. Saleh, Y. A. Al-Soud, L. Al-Kaabi, I. Ghosh and W. M. Nau, Tetrahedron Lett., 2011, 52, 5249.

20 M. Shaikh, S. D. Choudhury, J. Mohanty, A. C. Bhasikuttan, W. M. Nau and H. Pal, Chem. - Eur. J., 2009, 15, 12362.

21 N. Basílio, C. A. T. Laia and F. Pina, J. Phys. Chem. B, 2015, 119, 2749.
22 L. Zhu, H. Yan, X.-J. Wang and Y. J. Zhao, Org. Chem., 2012, 77, 10168.

23 M. Baroncini, C. Gao, V. Carboni, A. Credi, E. Previtera, M. Semeraro, M. Venturi and S. Silvi, Chem. - Eur. J., 2014, 20, 10737.

24 W. S. Jeon, A. Y. Ziganshina, J. W. Lee, Y. H. Ko, J.-K. Kang, C. Lee and K. Kim, Angew. Chem., Int. Ed., 2003, 42, 4097.

25 S. Sun, R. Zhang, S. Andersson, J. Pan, D. Zou, B. Akermark and L. Sun, J. Phys. Chem. B, 2007, 111, 13357.

26 D. Zou, S. Andersson, R. Zhang, S. Sun, B. Akermark and L. Sun, J. Org. Chem., 2008, 73, 3775.

27 New Trends in Fluorescence Spectroscopy: Applications to Chemical and Life Science, ed. B. Valeur and J.-C. Brochon, Springer-Verlag, Berlin Heidelberg New York, 2001.

28 J. W. Lee, S. Samal, N. Selvapalam, H.-J. Kim and K. Kim, Acc. Chem. Res., 2003, 36, 621.

29 J. Lagona, P. Mukhopadhyay, S. Chakrabarti and L. Isaacs, Angew. Chem., Int. Ed., 2005, 44, 4844.

30 W. M. Nau, M. Florea and K. Assaf, Isr. J. Chem., 2011, $51,559$.

31 E. V. Tulyakova, O. A. Fedorova, Y. V. Fedorov, G. Jonusauskas and A. V. Anisimov, Russ. Chem. Bull., 2007, 56, 2166.

32 E. V. Tulyakova, O. A. Fedorova, Y. V. Fedorov, G. Jonusauskas and A. V. Anisimov, J. Phys. Org. Chem., 2008, 21, 372.

33 O. A. Fedorova, E. Y. Chernikova, Y. V. Fedorov, E. N. Gulakova, A. S. Peregudov, K. A. Lyssenko, G. Jonusauskas and L. Isaacs, J. Phys. Chem. B, 2009, 113, 10149.

34 E. Chernikova, D. Berdnikova, Y. Fedorov, O. Fedorova, A. Peregudov and L. Isaacs, Chem. Commun., 2012, 48, 7256.

35 G. Parvari, O. Reany and E. Keinan, Isr. J. Chem., 2011, 51, 646.

36 A. C. Bhasikuttan, H. Pal and J. Mohanty, Chem. Commun., 2011, 47, 9959.

37 S. D. Choudhury, J. Mohanty, H. P. Upadhyaya, A. C. Bhasikuttan and H. Pal, J. Phys. Chem. B, 2009, 113, 1891.

38 Z. R. Grabowski, K. Rotkiewicz and W. Rettig, Chem. Rev., 2003, 103, 3899.

39 X. Cao, R. W. Tolbert, J. L. McHale and W. D. Edwards, J. Phys. Chem. A, 1998, 102, 2739.

40 B. Strehmel, H. Seifert and W. Rettig, J. Phys. Chem. B, 1997, 101, 2232.

41 H. Ephardt and P. Fromherz, J. Phys. Chem., 1989, 93, 7717. 42 S. Nad and H. Pal, J. Phys. Chem. A, 2001, 105, 1097.

43 S. Nad, M. Kumbhakar and H. Pal, J. Phys. Chem. A, 2003, $107,4808$.

44 M. Cigáň, J. Donovalová, V. Szöcs, J. Gašpar, K. Jakusová and A. Gáplovský, J. Phys. Chem. A, 2013, 117, 4870.

45 N. Ouerfelli, Z. Barhoumi and O. Iulian, J. Solution Chem., 2012, 41, 458.

46 P. J. Robinson and K. A. Holbrook, Unimolecular Reactions, Wiley-Interscience, London, 1972.

47 A. Pigliucci, E. Vauthey and W. Rettig, Chem. Phys. Lett., 2009, 469, 115.

48 B. Valeur, I. Leray, L. Zhao, V. Souchon, R. Métivier, P. Plaza, C. Ley, F. Lacombat and M. M. Martin, ChemPhysChem, 2010, 11, 2416. 
49 R. Jimenez, G. R. Fleming, P. V. Kumar and M. Maroncelli, Nature, 1994, 369, 471.

50 G. R. Fleming and M. Maroncelli, The Dynamics of Polar Solvation, in Ultrafast Phenomena VI, Springer-Verlag, Heidelberg, 1988.

51 M. Sajadi, M. Weinberger, H.-A. Wagenknecht and N. P. Ernsting, Phys. Chem. Chem. Phys., 2011, 13, 17768.
52 A. M. Brouwer, C. Frochot, F. G. Gatti, D. A. Leigh, L. Mottier, F. Paolucci, S. Roffia and G. W. H. Wurpel, Science, 2001, 291, 2124.

53 V. Balzani, M. Clemente-León, A. Credi, B. Ferrer, M. Venturi, A. H. Flood and J. F. Stoddart, Proc. Natl. Acad. Sci. U. S. A., 2006, 103, 1178. 